\title{
Discrepancies in Electrolyte Measurements by Direct and Indirect Ion Selective Electrodes due to Interferences by Proteins and Lipids
}

\author{
Parul Chopra ${ }^{1}$ Sudip Kumar Datta ${ }^{2, \odot}$ \\ 1Department of Hematology and Immunology, Dr. Lal PathLabs, \\ New Delhi, India \\ 2Department of Laboratory Medicine, All India Institute of Medical \\ Sciences, New Delhi, India
}

\begin{abstract}
Address for correspondence Sudip Kumar Datta, MBBS, MD (Biochemistry), DHM, Department of Laboratory Medicine, All India Institute of Medical Sciences, New Delhi 110029, India (e-mail: dr.sudipdatta@gmail.com).
\end{abstract}

J Lab Physicians:2020;12:84-91

\begin{abstract}
Keywords

- ISE

- electrolytes

- hyperproteinemia

- hypercholesterolemia

- hypertriglyceridemia

Objectives We aim to report the simultaneous effect of different protein and lipid concentrations on sodium $\left(\mathrm{Na}^{+}\right)$and potassium $\left(\mathrm{K}^{+}\right)$measurement by direct and indirect ion selective electrodes (dISE and iISE) in patient samples.

Materials and Methods $\mathrm{Na}^{+}$and $\mathrm{K}^{+}$were measured in 195 serum samples received in the laboratory using iISE by Roche Modular P800 autoanalyzer and using dISE by XI-921 ver. 6.0 Caretium electrolyte analyzer. Serum total protein (TP), cholesterol (Chol), and triglycerides (TG) were measured using conventional photometric methods on Roche Modular P800 autoanalyzer. Differences for each pair of results for $\mathrm{Na}^{+}$ (Diff_Na $\left.\mathrm{Na}^{+}=\left[\mathrm{Na}^{+}{ }_{\text {dISE- }} \mathrm{Na}^{+}{ }_{\text {iSEE }}^{+}\right]\right)$and $\mathrm{K}^{+}\left(\right.$Diff_- $\mathrm{K}^{+}=\left[\mathrm{K}^{+}{ }_{\text {dISE- }} \mathrm{K}^{+}{ }_{\text {ilSE }}\right]$ ) were calculated. Patient subgroups with high, normal, or low TP $(<5,5-7.9$, or $\geq 8 \mathrm{~g} / \mathrm{dL})$, Chol $(<150,150-299$, or $\geq 300 \mathrm{mg} / \mathrm{dL})$, or TG $(<150,150-299$, or $\geq 300 \mathrm{mg} / \mathrm{dL}$ ) were compared using analysis of variance. Note that $95 \%$ confidence interval of Diff_Na $\mathrm{Na}^{+}$and Diff_K $\mathrm{K}^{+}$were calculated to see the number of samples showing clinically significant differences.

Results Diff_Na ${ }^{+}(p=0.007)$ and Diff_K $\mathrm{K}^{+}(p=0.002)$ were found significant between samples with normal and high TP. However, effect of TG was not significant. Chol concentration affected Diff_Na+ ${ }^{+}$significantly between low versus normal $(p=0.002)$, and high versus normal $(p=0.031)$ Chol groups. Diff_K $\mathrm{K}^{+}$was significant $(p=0.009)$ between low versus normal Chol. Clinically relevant disagreement of $\geq|5| \mathrm{mmol} / \mathrm{L}$ for $\mathrm{Na}^{+}$was observed in high percentage of samples including all subcategories; however, for $\mathrm{K}^{+}$only $3.6 \%$ of the total samples showed disagreement of $\geq|0.5| \mathrm{mmol} / \mathrm{L}$. A multivariate regression equation based on fit regression model was also derived.

Conclusion Summarily, interchangeable use of electrolyte results from dISE and iISE is not advisable, especially in a setting of hyperproteinemia $(\geq 8 \mathrm{~g} / \mathrm{dL})$ or hypercholesterolemia ( $\geq 300 \mathrm{mg} / \mathrm{dL}$ ); more so for $\mathrm{Na}^{+}$.
\end{abstract}

\section{Introduction}

Measurement of serum electrolytes, sodium $\left(\mathrm{Na}^{+}\right)$and potassium $\left(\mathrm{K}^{+}\right)$, are one of the most frequently ordered tests in patients from emergency department or critical care and urgent reports are crucial for clinical decision-making. Most present-day electrolyte analyzers use ion selective electrode
(ISE)-based technologies, both in the clinical laboratories and also at the point-of-care (POC) setting. However, ISEs can be "direct" or "indirect"; direct ISEs (dISEs) allow interaction of serum sample directly with the ion-selective membrane, unlike in indirect ISEs (iISEs) which include a predilution step where the samples are diluted in the ratio of $1: 20$ or more to allow measurement with lower sample volumes and 
to expand the measurable concentration range. ${ }^{1}$ Because of their high capacity, iISEs are used in most of the autoanalyzers in clinical chemistry laboratories, whereas dISEs are used in POC devices. This introduces a method-dependent difference in the analytical results especially in the setting of serial monitoring and interchangeable use of results from two technologies.

The most important factor affecting the accuracy of results in case of iISE is the displacement of plasma water by proteins and lipids in cases of hyperproteinemia or hyperlipidemia, a phenomenon recognized as "electrolyte exclusion effect."2,3 Normally, these nonaqueous components constitute approximately $7 \%$ of the plasma volume. When they increase, iISE output, that is standardized for a predilution plasma water mass concentration of $0.93 \mathrm{~kg} / \mathrm{L}$, gives erroneously low results. The phenomenon of "pseudohyponatremia" has been well reported in the literature due to the effects of proteins and lipids. ${ }^{3,4}$ Contrarily, in dISE, since the sample is not prediluted, the measurement remains unaffected by nonaqueous phase variation. It gives a true estimate of the plasma electrolytes despite any changes in nonaqueous plasma components. The opposite effect, "pseudohypernatremia" has also been reported in the literature. ${ }^{5}$

With the recent proliferation of POC testing, clinicians are increasingly using electrolyte results from dISE and iISE interchangeably, sometimes confusing clinical decision making. Till date, no consensus has been achieved on the correlation of results from dISE and iISE, especially in the setting of abnormal solids in the serum. In the present study, we attempt to analyze the combined effect of protein and lipid concentrations on electrolyte analysis by these two commonly used technologies.

\section{Methods and Materials}

The present cross-sectional study was conducted in the clinical biochemistry and emergency laboratory at a tertiary care teaching hospital. In this study, 400 serum samples, which were received in the clinical biochemistry laboratory for electrolyte analysis, were screened. From these samples, 195 samples were included, which had been concurrently evaluated for serum protein, cholesterol, and triglyceride (TG) concentration.

Subgroups: These samples were further classified as per (1) serum total proteins (TPs) $\geq 8 \mathrm{~g} / \mathrm{dL}$, between 5 and $7.9 \mathrm{~g} /$ $\mathrm{dL}$, and also $<5 \mathrm{~g} / \mathrm{dL}$; (2) serum total TG $\geq 300 \mathrm{mg} / \mathrm{dL}$, between 150 and 299, and < $150 \mathrm{mg} / \mathrm{dL}$; and (3) serum total cholesterol (TC) $\geq 300 \mathrm{mg} / \mathrm{dL}$, between 150 and 299 , and $<150 \mathrm{mg} / \mathrm{dL}$.

\section{Measurements}

- Serum $\mathrm{Na}^{+}$and $\mathrm{K}^{+}$were measured by both Roche Modular P800 autoanalyzer (Roche Diagnostics) (iISE) and XI-921 (ver. 6.0, Caretium Medical Instruments Co.) (dISE).

- Other parameters like serum TPs were measured by Biuret method; serum TC by cholesterol oxidase-peroxidase
(CHOD- PAP) method; and serum TG by glycerol-3-phosphate oxidase-peroxidase (GPO-PAP) method measured by the Roche Modular P800 autoanalyzer.

Samples with visible hemolysis, icterus, or lipemia were excluded. Routine quality control was performed daily as per accepted guidelines on both the analyzers.

\section{Analysis}

The data was compiled in Microsoft Excel and analyzed using SPSS software version 20 (IBM Corporation).

Difference between dISE and iISE was calculated for serum $\mathrm{Na}^{+}\left(\right.$Diff_Na $\left.\mathrm{Na}^{+}=\left[\mathrm{Na}^{+}{ }_{\text {dISE }}-\mathrm{Na}^{+}{ }_{\text {iISE }}\right]\right)$ and $\mathrm{K}^{+}\left(\right.$Diff_K $\left.\mathrm{K}^{+}=\left[\mathrm{K}_{\text {dISE }}^{+}-\mathrm{K}_{\text {iISE }}^{+}\right]\right)$ for each pair of results. Comparison was done between different patient subgroups with normal or abnormal serum proteins, serum cholesterol, and serum TG using analysis of variance test. A $p$-value of $<0.05$ was considered significant. The dISE and iISE results were compared using Pearson's correlation and interinstrument agreement was studied by making the Bland-Altman plots.

For evaluation of analytical variation, laboratory coefficients of variation (CVs) were calculated for $\mathrm{Na}^{+}$and $\mathrm{K}^{+}$using 30 data points from previous month's quality control runs having manufacturer's target values of 135 and $111 \mathrm{mmol} / \mathrm{L}$ for $\mathrm{Na}^{+}$and 6.92 and $3.77 \mathrm{mmol} / \mathrm{L}$ for $\mathrm{K}^{+}$. For iISE, CV\% of 1.4 and $1 \%$ were obtained for $\mathrm{Na}^{+}$and $\mathrm{K}^{+}$, respectively, whereas for dISE, the same were 1 and $0.6 \%$, respectively, using similar methods with quality control material having manufacturer's target mean of 145 and $5.0 \mathrm{mmol} / \mathrm{L}$ for $\mathrm{Na}^{+}$and $\mathrm{K}^{+}$, respectively. These CVs were simplified and applied at $\mathrm{Na}^{+}$and $\mathrm{K}^{+}$value of 140 and $4 \mathrm{mmol} / \mathrm{L}$, respectively, to generate an equivalent standard deviation (SD) for each analytic method. Note that 95\% confidence intervals (CIs) for difference between dISE and iISE (dISE-iISE) were then calculated. To find out CI limits for a clinically important difference between separate samples within individual subjects over time, assumed biologic variance component was taken to be 0.6 and $4.6 \%$, respectively, for $\mathrm{Na}^{+}$and $\mathrm{K}^{+}$and was incorporated to this analytical variation using a strategy similar to Dimeski et al..$^{6-8}$ Using the formula:

$$
\begin{aligned}
95 \%_{\text {(dISE-iISE) }} \mathrm{mmol} / \mathrm{L}= & \pm 1.96\left[\left(\mathrm{SD}_{\text {(dISE) }}^{2}+\mathrm{SD}_{\left.{ }_{(\text {biological) }}^{2}\right)}\right.\right. \\
& \left.+\left(\mathrm{SD}_{\text {(ilSE) }}^{2}+\mathrm{SD}_{(\text {biological) }}^{2}\right)\right]^{1 / 2}
\end{aligned}
$$

95\% CIs for dISE-iISE for both $\mathrm{Na}^{+}$and $\mathrm{K}^{+}$were calculated. Disagreement of $|5| \mathrm{mmol} / \mathrm{L}$ or higher for $\mathrm{Na}^{+}$and $|0.5| \mathrm{mmol} / \mathrm{L}$ or higher for $\mathrm{K}^{+}$was considered clinically significant. We calculated the number of samples showing clinically significant disagreement that is $|5| \mathrm{mmol} / \mathrm{L}$ or higher for $\mathrm{Na}^{+}$and $|0.5| \mathrm{mmol} / \mathrm{L}$ or higher for $\mathrm{K}^{+}$in each subgroup, classified as described above.

Finally, we used the fit regression model on Minitab 17 software to develop a regression equation for Diff_Na ${ }^{+}$and Diff_K $\mathrm{K}^{+}$with all the three variables taken into consideration. 


\section{Results}

- Fig. 1 depicts the scatterplots of serum $\mathrm{Na}^{+}$and $\mathrm{K}^{+}$concentration obtained by dISE and iISE. The plots reveal Pearson's correlation coefficient $(r)$ of $0.635, p<0.001$ for $\mathrm{Na}^{+}$and $r$ of $0.951, p<0.001$ for $\mathrm{K}^{+}$, respectively ( - Fig. 1 ), signifying much more incomparability in $\mathrm{Na}^{+}$results between the two technologies. -Fig. 2 are the Bland-Altman plots showing the difference of serum $\mathrm{Na}^{+}$and $\mathrm{K}^{+}$concentration measured by dISE and iISE plotted against the mean results obtained by the two methods along with the $95 \%$ limits of agreement. As suggested by Giavarina, if the variability of the differences were linked to analytical imprecision only, then the average of these differences would have been zero. ${ }^{9}$ This was certainly not observed in our results for $\mathrm{Na}^{+}$that showed an average difference of $6 \mathrm{mmoL} / \mathrm{L}$. This bias could be constant over the whole analytical range or might be an average result from different problems at different concentrations.

Based on our hypothesis, we assumed that these variations were due to the differences of proteins and lipids in the samples and hence proceeded for analysis of the results in the different subgroups. - Table 1 shows the differences obtained between dISE and iISE in $\mathrm{Na}^{+}$and $\mathrm{K}^{+}$measurements in different subgroups of samples. Significant differences were observed for both $\mathrm{Na}^{+}(p=0.025)$ and $\mathrm{K}^{+}(p=0.007)$ concentration by dISE and iISE between samples with different protein concentrations. However, effect of serum TG concentration was not evident on Diff_K $\mathrm{K}^{+}(p=0.074)$ or Diff_ $\mathrm{Na}^{+}$. Cholesterol concentration was observed to significantly affect the differences for both serum $\mathrm{Na}^{+}(p=0.006)$ and $\mathrm{K}^{+}(p=0.028)$ concentration.
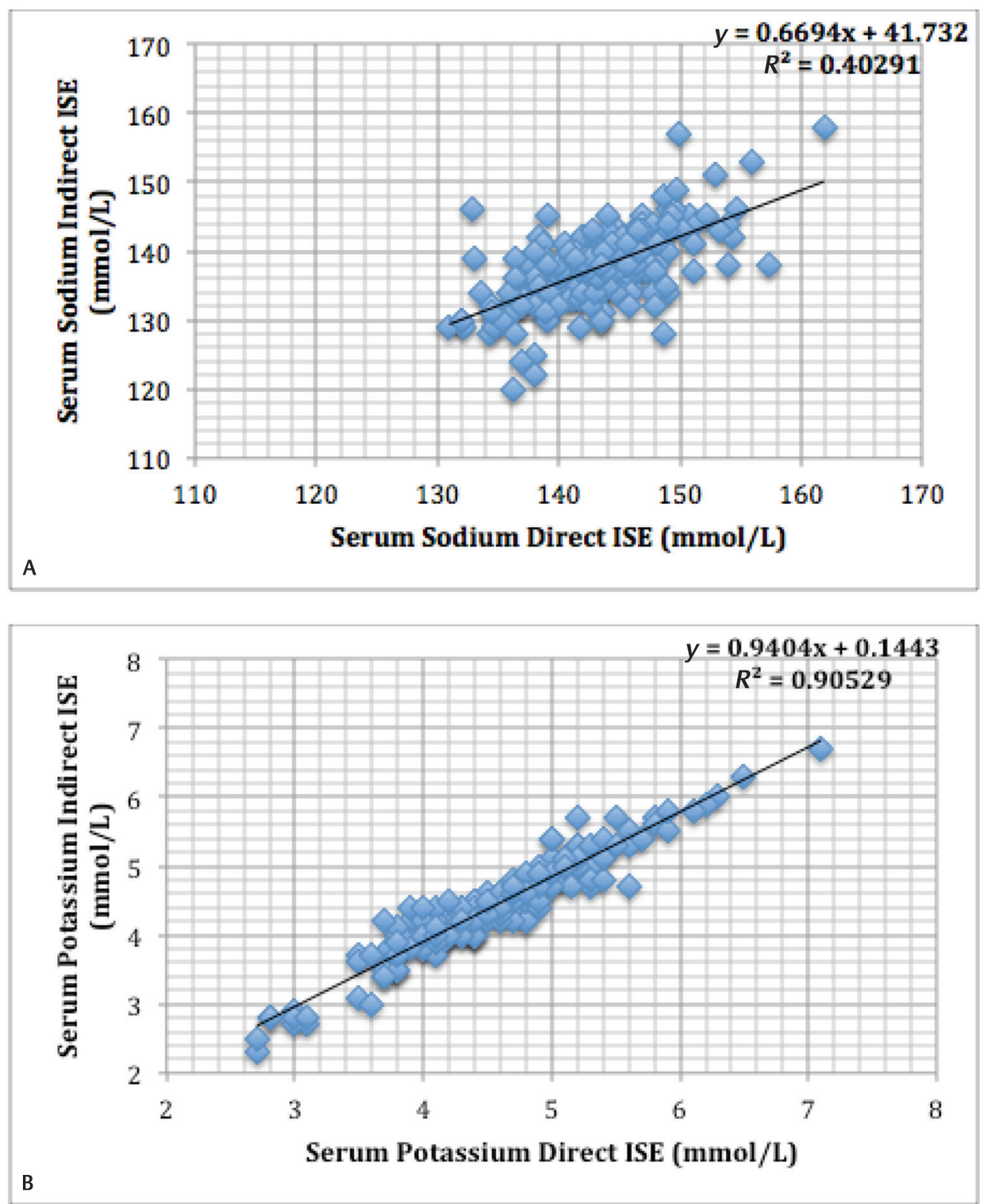

Fig. 1 (A) Comparison of direct ion selective electrode (dISE) and indirect ion selective electrode (iISE) for the measurement of serum $\mathrm{Na}^{+}$. Pearson's correlation coefficient $(r)$ : $(r: 0.635, p<0.001)$. (B) Comparison of dISE and iISE for the measurement of serum K+. Pearson's correlation coefficient $(r):(r: 0.951, p<0.001)$. 

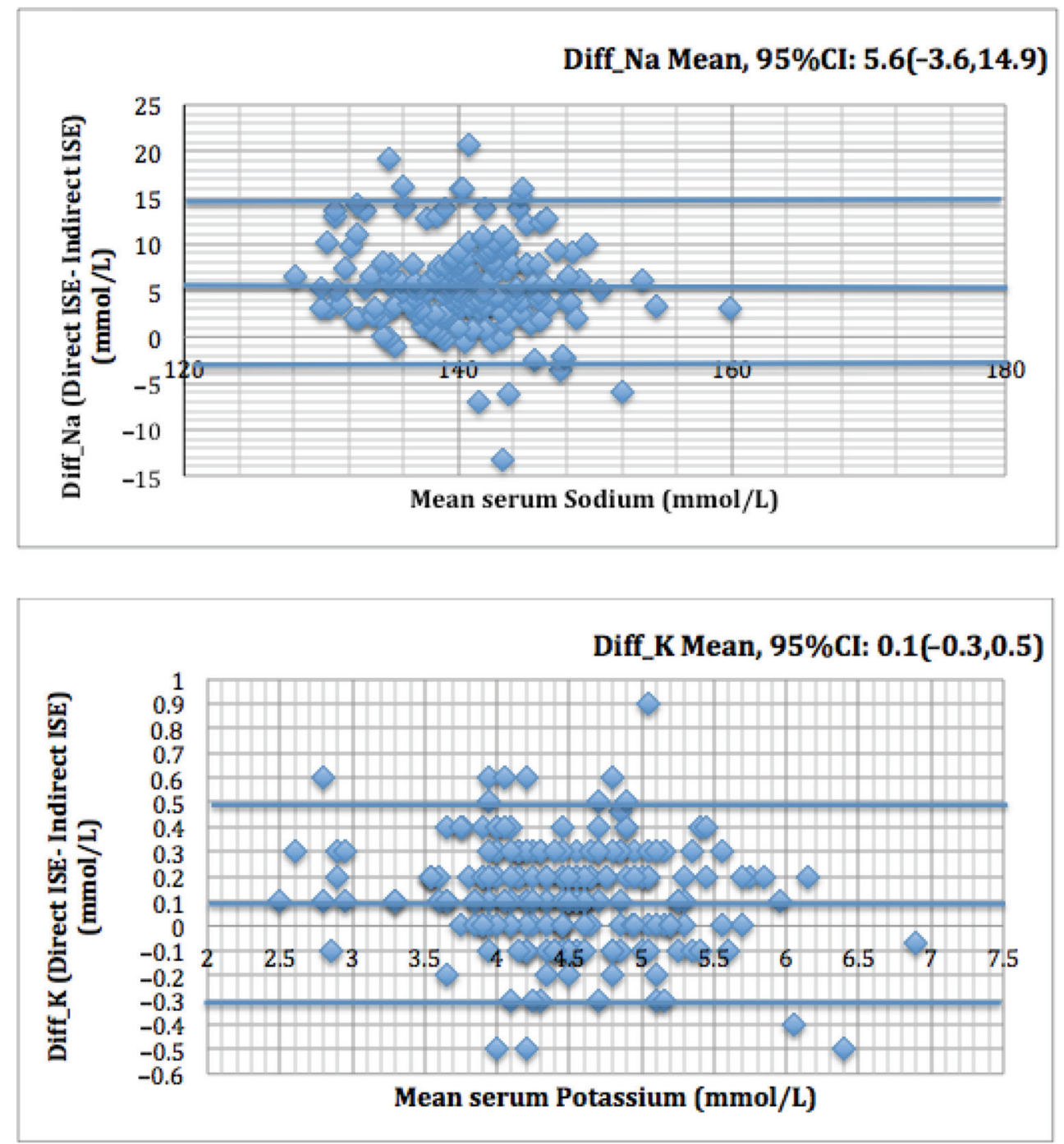

Fig. 2 (A) Bland-Altman plot showing difference of serum $\mathrm{Na}^{+}$concentration measured by direct ion selective electrode (dISE) and indirect ion selective electrode (iISE) against mean of two methods showing the $95 \%$ limits of agreement. (B) Bland-Altman plot showing difference of serum $\mathrm{K}^{+}$concentration measured by dISE and ilSE against mean of two methods showing the $95 \%$ limits of agreement.

Table 1 Differences obtained between direct and indirect ISE electrolyte measurement in patient subgroups

\begin{tabular}{|c|c|c|c|}
\hline Protein subgroups (g/dL) & $<5$ & $5-7.9$ & $\geq 8$ \\
\hline Number of samples & 43 & 96 & 56 \\
\hline Difference $\mathrm{Na}^{+}$(dISE-iISE) & $5.6 \pm 4.9$ & $4.9 \pm 3.4$ & $7.0 \pm 5.8^{\mathrm{a}}$ \\
\hline Difference $\mathrm{K}^{+}$(dISE-iISE) & $0.14 \pm 0.17$ & $0.07 \pm 0.22$ & $0.19 \pm 0.21^{\mathrm{a}}$ \\
\hline TG subgroups (mg/dL) & $<150$ & $150-299$ & $\geq 300$ \\
\hline Number of samples & 86 & 53 & 56 \\
\hline Difference $\mathrm{Na}^{+}$(dISE-iISE) & $5.0 \pm 4.6$ & $6.0 \pm 4.7$ & $6.1 \pm 4.6$ \\
\hline Difference $\mathrm{K}^{+}$(dISE-iISE) & $0.09 \pm 0.22$ & $0.11 \pm 0.23$ & $0.18 \pm 0.18$ \\
\hline Cholesterol subgroups (mg/dL) & $<150$ & $150-299$ & $\geq 300$ \\
\hline Number of samples & 78 & 72 & 45 \\
\hline Difference $\mathrm{Na}^{+}$(dISE-ilSE) & $6.6 \pm 4.5^{a}$ & $4.2 \pm 4.3$ & $6.1 \pm 4.8^{\mathrm{a}}$ \\
\hline Difference $\mathrm{K}^{+}$(dISE-ilSE) & $0.16 \pm 0.23^{\mathrm{a}}$ & $0.07 \pm 0.21$ & $0.14 \pm 0.17$ \\
\hline
\end{tabular}

Abbreviations: dISE, direct ion selective electrode; ilSE, indirect ion selective electrode; TG, triglycerides.

Note: Values of Diff_Na ${ }^{+}$and Diff_K $\mathrm{K}^{+}$expressed as mean \pm standard deviation. Analysis of variance (ANOVA) was done to compare the subgroup data. aSignificant at $p<0.05$ when compared with the middle group (i.e., $5-7.9 \mathrm{~g} / \mathrm{dL}$ for proteins, and $150-299 \mathrm{mg} / \mathrm{dL}$ for both TG and cholesterol). 
Table 2 Sample distribution within subgroups with absolute sodium differences $5 \mathrm{mmol} / \mathrm{L}$ or higher and potassium differences $0.5 \mathrm{mmol} / \mathrm{L}$ or higher between direct and indirect ISE method

\begin{tabular}{|c|c|c|c|c|c|}
\hline Categories & Number (total) & $\begin{array}{l}\mathrm{Na}^{+}(\mathrm{dISE}-\mathrm{ilSE}) \\
\geq|5| \mathrm{mmol} / \mathrm{L} \\
\text { No of samples }(\% \mathrm{a})\end{array}$ & $\begin{array}{l}\mathrm{Na}^{+}(\mathrm{dISE}-\mathrm{ilSE}) \\
<|5| \mathrm{mmol} / \mathrm{L} \\
\text { No of samples }(\% \mathrm{a})\end{array}$ & $\begin{array}{l}\mathrm{K}^{+}(\mathrm{dISE}-\mathrm{ilSE}) \\
\geq|0.5| \mathrm{mmol} / \mathrm{L} \\
\text { No of samples }\left(\%{ }^{\mathrm{a}}\right)\end{array}$ & $\begin{array}{l}\mathrm{K}^{+}(\mathrm{dISE}-\mathrm{ilSE}) \\
<|0.5| \mathrm{mmol} / \mathrm{L} \\
\text { No of samples }\left(\%^{\mathrm{a}}\right)\end{array}$ \\
\hline Protein $(\mathrm{g} / \mathrm{dL})$ & 195 & $106(54.4 \%)$ & $89(45.6 \%)$ & $7(3.6 \%)$ & $188(96.4 \%)$ \\
\hline$<5$ & 43 & $23(53.5 \%)$ & 20 (46.5\%) & $0(0 \%)$ & 43 (100\%) \\
\hline $5-7.9$ & 96 & $44(45.8 \%)$ & $52(54.2 \%)$ & $4(4.2 \%)$ & $92(95.8 \%)$ \\
\hline$\geq 8$ & 56 & $39(69.6 \%)$ & $17(30.4 \%)$ & $3(5.4 \%)$ & $53(94.6 \%)$ \\
\hline $\begin{array}{l}\text { Total serum } \\
\text { cholesterol (mg/dL) }\end{array}$ & 195 & $106(54.4 \%)$ & $89(45.6 \%)$ & $7(3.6 \%)$ & 188 (96.4\%) \\
\hline $0-149$ & 78 & 46 (59\%) & $32(41 \%)$ & $5(6.4 \%)$ & 73 (93.6\%) \\
\hline $150-299$ & 72 & $34(47.2 \%)$ & $38(52.8 \%)$ & $2(2.8 \%)$ & 70 (97.2\%) \\
\hline$\geq 300$ & 45 & $26(57.8 \%)$ & $19(42.2 \%)$ & $0(0 \%)$ & 45 (100\%) \\
\hline $\begin{array}{l}\text { Total serum } \\
\text { TG }(\mathrm{mg} / \mathrm{dL})\end{array}$ & 195 & $106(54.4 \%)$ & $89(45.6 \%)$ & $7(3.6 \%)$ & $188(96.4 \%)$ \\
\hline $0-149$ & 86 & 44 (51.2\%) & $42(48.8 \%)$ & $1(1.2 \%)$ & 85 (98.8\%) \\
\hline $150-299$ & 53 & $29(54.7 \%)$ & $24(45.3 \%)$ & $4(7.5 \%)$ & 49 (92.5\%) \\
\hline$\geq 300$ & 56 & $33(58.9 \%)$ & $23(41.1 \%)$ & $2(3.6 \%)$ & $54(96.4 \%)$ \\
\hline
\end{tabular}

Abbreviations: dISE, direct ion selective electrode; ilSE, indirect ion selective electrode; TG, triglycerides.

apercentages are the percent of samples from each subcategory.

The number and percentage of samples showing clinically significant disagreement as calculated above, that is, $|5|$ $\mathrm{mmol} / \mathrm{L}$ or higher for serum $\mathrm{Na}^{+}$and $|0.5| \mathrm{mmol} / \mathrm{L}$ or higher for serum $\mathrm{K}^{+}$in each subgroup of proteins, TG, and cholesterol (-Table 2) were calculated. It was seen that clinically significant disagreement was seen in lesser number of samples, that is, (3.6\% of the total samples) in case of serum $\mathrm{K}^{+}$individually in all subcategories of serum proteins, serum cholesterol, as well as serum TG. On the other hand, high percentage of samples $(54.4 \%)$ showed clinically significant difference in concentration of serum $\mathrm{Na}^{+}$including all subcategories of serum proteins, serum cholesterol, as well as serum TG. The effect of proteins was most pronounced on serum $\mathrm{Na}^{+}$showing disagreement in most of the samples.

There were only 3 samples out of 195 having low concentration of both TP and TG. Two out of these three had clinically significant difference in $\mathrm{Na}^{+}$but not in $\mathrm{K}^{+}$when compared by measurement with both the methods. However, there was only one sample with high TP and TG. It did not show any significant difference in values of serum $\mathrm{Na}^{+}$and $\mathrm{K}^{+}$ when measured by both the methods.

Since clinically significant differences were mostly seen in $\mathrm{Na}^{+}$values between the two methods, this difference was plotted against the serum TPs ( $\mathbf{- F i g . ~ 3 A}$ ), cholesterol ( - Fig. 3B), and TG (-Fig. 3C). Finally, using the fit regression model on Minitab 17 software we developed a regression equation for Diff_Na+ ${ }^{+}$with all the three variables taken into consideration: Diff_Na ${ }^{+}=1.89+0.427 \mathrm{TP}+0.00171 \mathrm{TGs}+$ 0.00266 cholesterol and Diff_K $\mathrm{K}^{+}=-0.038+0.0184 \mathrm{TP}+$ $0.000075 \mathrm{TGs}+0.000120$ cholesterol. However, the model has a fair share of large residuals and unusual data points.

\section{Discussion}

In the present study, we aimed at studying the effect of serum protein and lipid concentration on electrolyte measurement to find out whether dISE and iISE can be used interchangeably. Usually, POC instruments use dISE and the automated analyzers used in central laboratories use iISE for the measurements of $\mathrm{Na}^{+}$and $\mathrm{K}^{+}$. Since, use of iISE involves a predilution step of the sample and calculates the final result based on the assumption of a constant $7 \%$ volume of the serum to be dissolved solids, this impacts the agreeability of the results obtained from the two platforms in settings of high or low protein or lipid content in the serum. In the present study, we look into the agreement of $\mathrm{Na}^{+}$and $\mathrm{K}^{+}$measurements under different conditions of proteinemia and lipemia. We also try to come up with a corrective equation using the serum TP, cholesterol, and TG contents.

First, we compared the overall agreement of $\mathrm{Na}^{+}$and $\mathrm{K}^{+}$ obtained by dISE and iISE by doing a correlation. It gave a Pearson's correlation coefficient of $r: 0.635, p<0.001$ for $\mathrm{Na}^{+}$ measurement and $\mathrm{r}$ : 0.951, $p<0.001$ for $\mathrm{K}^{+}$measurement (-Fig. 1). Many other studies have compared the automated analyzers and POC blood gas analyzers for measuring serum electrolytes. ${ }^{8-13}$ In one study on 84 samples, the authors compared the mean difference between $\mathrm{Na}^{+}$and $\mathrm{K}^{+}$measured by dISE and iISE. They have shown unacceptable interanalyzer agreement existed for both $\mathrm{Na}^{+}$and $\mathrm{K}^{+}$, with a bias of- 0.97 to 10.05 and 0.150 to 0.352 , respectively. The associated correlation coefficients were 0.90 and $0.88 .^{10}$

To find out the interference caused by different levels of protein, we subdivided the patient samples into three groups 

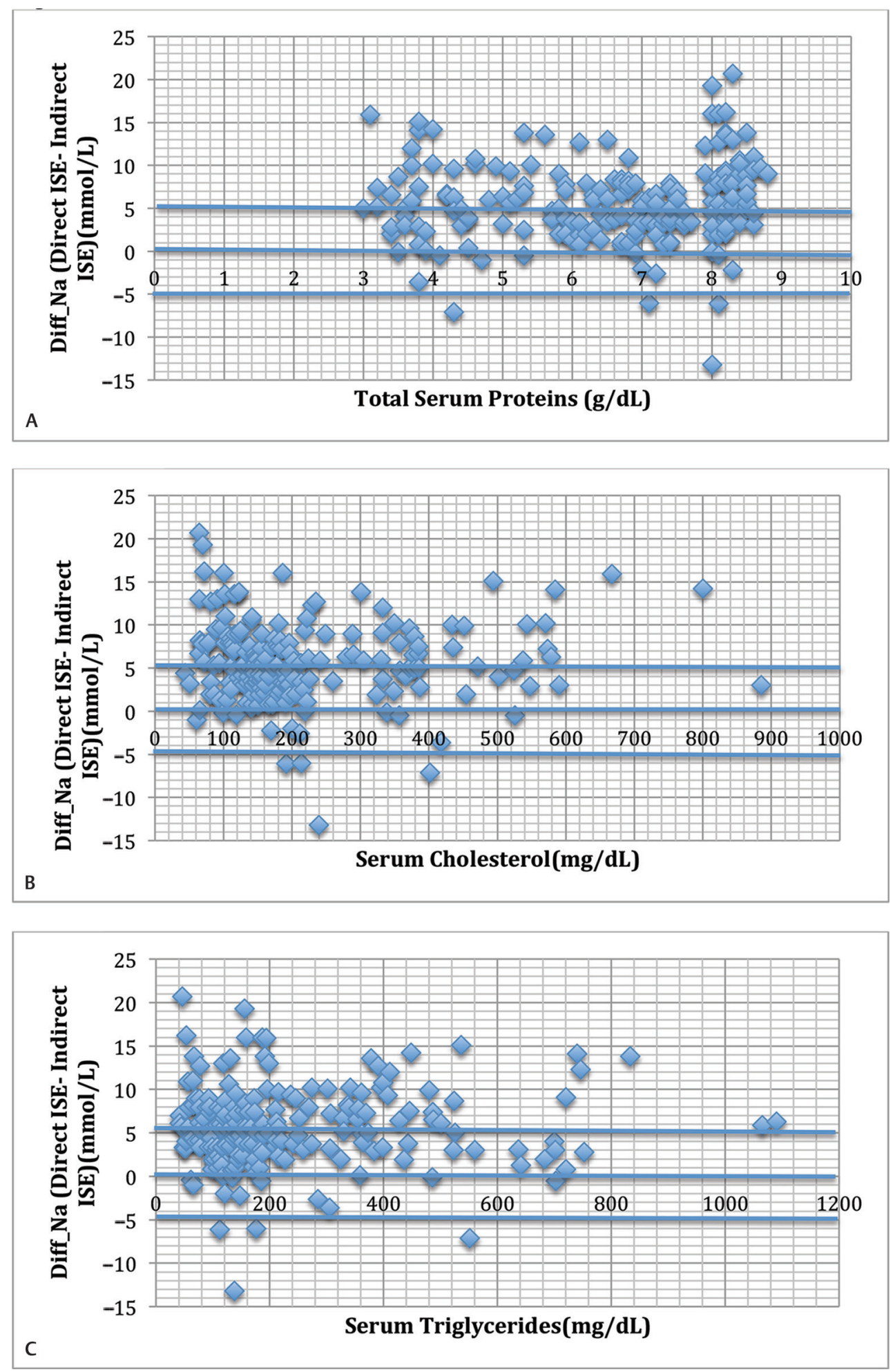

Fig. 3 (A) Difference between sodium measurements by direct and indirect ion selective electrode (ISE) plotted against different levels of total serum proteins. (B) Difference between sodium measurements by direct and indirect ISE plotted against different levels of total serum cholesterol. (C) Difference between sodium measurements by direct and indirect ISE plotted against different levels of total serum triglycerides.

with different protein concentrations $<5,5$ to 7.9 , and $\geq 8 \mathrm{~g} / \mathrm{dL}$. Our results show that the differences obtained between dISE and iISE were significant for both $\mathrm{Na}^{+}(p=0.005)$ and $\mathrm{K}^{+}(p=0.003)$ between samples of these subgroups. A few other studies show the effect of electrolyte exclusion by studying the effect of proteins ${ }^{14,15}$ on electrolyte measurement.
Pseudo-hyper effect due to low protein concentration and a pseudo-hypo effect with high plasma protein concentrations in all three analytes $\mathrm{Na}^{+}, \mathrm{K}^{+}$, and $\mathrm{Cl}^{+}$have also been shown. The maximum disagreement was shown by plasma $\mathrm{Na}^{+}$measurement against different TP concentrations. Accurate predictive values were not calculated by the authors with changes in 
protein concentrations as the relationship was nonlinear. ${ }^{14}$ Somewhat strong correlation between differences in dISE and iISE values of $\mathrm{Na}^{+}$measurements and albumin concentration was found in another study done on 300 critically ill patients, concluding that central laboratory (having iISE) and intensive care unit assays (dISE) are different for $\mathrm{Na}^{+}$in all ways, analytically, statistically, and clinically. ${ }^{15}$

In one study, where patients were being given intravenous immunoglobulin (IVIG) infusion raised serum proteins and postinfusion serum $\mathrm{Na}^{+}$results were lower measured by iISE, though not significant (pre- and post-IVIG infusion: $141 \pm$ $5 \mathrm{mEq} / \mathrm{L}$ vs. $138 \pm 2 \mathrm{mEq} / \mathrm{L}$ by iISE). ${ }^{16}$ In another study from 190 patients with hypoproteinemia, serum $\mathrm{Na}^{+}$and $\mathrm{K}^{+}$measurements were higher $(p<0.0001)$ using iISE $(140.0 \pm 5.0$ and $4.5 \pm 0.6$, respectively) compared with dISE (136.5 \pm 5.2 and $4.5 \pm 0.6$, respectively). The calculated difference between iISE and dISE values for $\mathrm{Na}^{+}$increased as TP concentration decreased. They also found out that iISE as compared with dISE had wrongly classified $28 \%$ of samples. Out of these, $19 \%$ were classified as pseudonormonatremia, $8 \%$ as pseudohypernatremia, $0.8 \%$ as pseudonormokalemia, and $0.4 \%$ as pseudohyperkalemia resulting in significant misclassification of electrolyte, mainly $\mathrm{Na}^{+}{ }^{17}$

Next, to study the effect of lipids on electrolyte measurement, we subdivided patients with serum TG and cholesterol concentration $\geq 300$, between 150 and 299, and < $150 \mathrm{mg} / \mathrm{dL}$. Not many studies have shown the effect of lipids ${ }^{18}$ on electrolyte exclusion. One such study showed that hyperlipidemia caused errors in iISE measurements. All three electrolytes, that is, $\mathrm{Na}^{+}, \mathrm{K}^{+}$, and $\mathrm{Cl}^{-}$, determined by the iISE as a result of hyperlipidemia showed artifactual decrease in values: for every $10 \mathrm{mmol} / \mathrm{L}$ increase in total lipid concentration, $\mathrm{Na}^{+}$and $\mathrm{Cl}^{+}$decreased by $1 \mathrm{mmol} / \mathrm{L}$ and $\mathrm{K}^{+}$by $0.04 \mathrm{mmol} / \mathrm{L}^{18}$ They recommended that if the specimen is overtly lipemic or viscous it can be ultracentrifuged prior to analysis by indirect measurement of the aqueous part or infranatant. When dISE methods and ultracentrifuges are unavailable, use of corrective formulae to handle severely lipemic samples had been suggested. ${ }^{18}$

Another study showed the effect of artificially induced lipemia and checked for its interference in measurement of electrolytes by two different instruments both measuring electrolytes by dISE. They showed a significant decrease in the concentration of $\mathrm{Na}^{+}$and $\mathrm{K}^{+}$with increased lipemia showing a drift in the results. ${ }^{19}$

We have studied the effect of both proteins as well as lipids on the measurement of electrolytes by both dISE and iISE showing a high variation in results by both the methods that can be seen in the Bland-Altman plots showing disagreement or wider range of $95 \% \mathrm{CI}$ especially in case of serum $\mathrm{Na}^{+}$.

To ensure accuracy in our results, we used external quality assurance program for our autoanalyzers and achieved good results. However, since the dISE instrument was not enrolled with any External Quality Assurance Services program, we ensured accuracy by split sample testing and comparison with iISE. We also used the controls of autoanalyzers as sample in the dISE instrument after every 40 samples and checked whether the value was within range.

However, the matrix of the calibrators used is not the same as the human samples which is a limitation and can affect the results because apart from the proteins and lipids there are other cations and anions that can interact with the membrane and alter the results differently in dISE and iISE. In our study, we have considered a difference of more than \pm 5 and $\pm 0.5 \mathrm{mmol} / \mathrm{L}$ in $\mathrm{Na}^{+}$and $\mathrm{K}^{+}$, respectively, when measured by dISE and iISE as clinically significant difference based on the calculations taking $95 \% \mathrm{CI}$ as our limit. This limit is well within range given by the U.S. Clinical Laboratory Improvement Amendments (CLIA) 1988 guidelines for $\mathrm{K}^{+}{ }^{20}$ For $\mathrm{Na}^{+}$, the limit given by the CLIA guidelines is $\pm 4 \mathrm{mmol} / \mathrm{L}^{15}$ In spite of taking $\pm 5 \mathrm{mmol} / \mathrm{L}$ as our limit, which is more than the recommended limit, the number of samples showing disagreement were high. This difference also takes into account the biological variation in the samples. Any difference less than this was considered not to be due to analytical errors and hence acceptable. The percentage of samples showing agreement between dISE and iISE concentration were much higher in case of $\mathrm{K}^{+}$in all ranges of proteins, lipids, and cholesterol. However, the values of serum $\mathrm{Na}^{+}$showed disagreement in a much greater number of samples. This disagreement can have large clinical implications in case of critically ill patients or those with electrolyte disturbances. Though it may be unimportant in other group of patients, serial monitoring of patients if done by different methods, that is, dISE and iISE, can cause confusion or wrong decisions to be taken due to their disagreeing results.

Several reports have been published till date, showing correlation of high protein or lipid levels with pseudohypoproteinemia in iISE; however, in our study we tried to evaluate the simultaneous effect of serum TP, TC, and TG on $\mathrm{Na}^{+}$ and $\mathrm{K}^{+}$estimation. Contrary to our expectations based on previous literature, iISE and dISE results appear to match better at higher protein and TG concentrations. This probably is observed due to combined effects of TP, TC, and TG and other unknown factors present in various concentration ranges in the patient samples. For example, patients having high concentration of TG may have had normal to low concentrations of TC or TP. Interferences from medications, etc. cannot also be ruled out. The regression equation for Diff_Na is an attempt to look into the individual proportion of effects due to the known individual factors, however, needs further studies for validation.

Normal electrolyte concentration falsely reported as decreased or increased as normal can have serious consequences for clinical safety. These can cause potential errors in clinical decision-making and patient management. These can be avoided by electrolyte measurements done either by direct potentiometry or using the same method every time while monitoring the concentrations of same patient to avoid ambiguous results. Also, if result from a lipemic or hyperproteinemic sample is recognized as being misleading, one suggested approach is to estimate the serum water fraction. ${ }^{17,21}$ 


\section{Conclusion}

Interchangeable use of electrolytes results from dISE and iISE is not advisable in a setting of hyperproteinemia or hypertriglyceridemia. No correlation could be established: hence, other factors may also play a role in the development of discrepancies

\section{Authors' Contributions}

Dr. Sudip Kumar Datta: Conceptualization, analysis and interpretation of results, writing, editing, and approval of manuscript. Dr. Parul Chopra: Sample collection, data entry, statistical analysis and interpretation, writing, editing, and approval of manuscript.

\section{Conflict of Interest}

There are no financial conflicts of interest to disclose. The authors declare that there is no conflict of interest regarding the publication of this article.

\section{Acknowledgments}

We would like to thank Dr. Abhirup Sarkar, Junior Resident, and Dr. Dharambeer Singh Mahor, Senior Resident, in the Department of Laboratory Medicine, AIIMS, who helped in sample collection and data entry. We would also like to thank our laboratory staff for their cooperation while conducting the study. Since the study was conducted on residual samples coming for routine biochemistry tests in the laboratory, ethical clearance was not required.

\section{References}

1 Schindler EI, Scott MG, Physiology and disorders of water, electrolyte, and acid-base metabolism. In: Burtis CA, Bruns DE, eds. Tietz Fundamentals of Clinical Chemistry and Molecular Diagnostics. 7th ed. St. Louis, MO: Elsevier Saunders; 2006: 680-699

2 Ladenson JH, Apple FS, Koch DD. Misleading hyponatremia due to hyperlipemia: a method-dependent error. Ann Intern Med 1981;95(6):707-708

3 Ladenson JH, Apple FS, Aguanno JJ, Koch DD. Sodium measurements in multiple myeloma: two techniques compared. Clin Chem 1982;28(12):2383-2386

4 Fortgens P, Pillay TS. Pseudohyponatremia revisited: a modern-day pitfall. Arch Pathol Lab Med 2011;135(4):516-519

5 Lang T, Prinsloo P, Broughton AF, Lawson N, Marenah CB. Effect of low protein concentration on serum sodium measurement: pseudohypernatraemia and pseudonormonatraemia! Ann Clin Biochem 2002;39(Pt 1) :66-67
6 Desirable Biological Variation Database specifications Westgard. Available at: https://www.westgard.com/biodatabase1.htm. Accessed May 15, 2020

7 Jones GRD. Critical difference calculations revised: inclusion of variation in standard deviation with analyte concentration. Ann Clin Biochem 2009;46(Pt 6) :517-519

8 Dimeski G, Morgan TJ, Presneill JJ, Venkatesh B. Disagreement between ion selective electrode direct and indirect sodium measurements: estimation of the problem in a tertiary referral hospital. J Crit Care 2012;27(3):326.e9-326.e16

9 Giavarina D. Understanding Bland Altman analysis. Biochem Med (Zagreb) 2015;25(2):141-151

10 Budak YU, Huysal K, Polat M. Use of a blood gas analyzer and a laboratory autoanalyzer in routine practice to measure electrolytes in intensive care unit patients. BMC Anesthesiol 2012;12(1):17

11 Jain A, Subhan I, Joshi M. Comparison of the point-of-care blood gas analyzer versus the laboratory auto-analyzer for the measurement of electrolytes. Int J Emerg Med 2009;2(2):117-120

12 Zhang JB, Lin J, Zhao XD. Analysis of bias in measurements of potassium, sodium and hemoglobin by an emergency department-based blood gas analyzer relative to hospital laboratory autoanalyzer results. PLoS One 2015;10(4):e0122383

13 Solak Y. Comparison of serum sodium levels measured by blood gas analyzer and biochemistry autoanalyzer in patients with hyponatremia, eunatremia, and hypernatremia. Am J Emerg Med 2016;34(8):1473-1479

14 Dimeski G, Barnett RJ. Effects of total plasma protein concentration on plasma sodium, potassium and chloride measurements by an indirect ion selective electrode measuring system. Crit Care Resusc 2005;7(1):12-15

15 Story DA, Morimatsu H, Egi M, Bellomo R. The effect of albumin concentration on plasma sodium and chloride measurements in critically ill patients. Anesth Analg 2007;104(4):893-897

16 Kim G-H. Pseudohyponatremia: does it matter in current clinical practice? Electrolyte Blood Press 2006;4(2):77-82

17 Chow E, Fox N, Gama R. Effect of low serum total protein on sodium and potassium measurement by ion-selective electrodes in critically ill patients. Br J Biomed Sci 2008;65(3): 128-131

18 Dimeski G, Mollee P, Carter A. Effects of hyperlipidemia on plasma sodium, potassium, and chloride measurements by an indirect ion-selective electrode measuring system. Clin Chem 2006;52(1):155-156

19 Sen S. A study on effect of lipemia on electrolyte measurement by direct ion selective electrode method. J Biomol Res Ther 2016;5(2):142

20 Ehrmeyer SS, Laessig RH, Leinweber JE, Oryall JJ. 1990 Medicare/CLIA final rules for proficiency testing: minimum intralaboratory performance characteristics (CV and bias) needed to pass. Clin Chem 1990;36(10):1736-1740

21 Waugh WH. Utility of expressing serum sodium per unit of water in assessing hyponatremia. Metabolism 1969;18(8): 706-712 